\title{
Beyond shadow of doubt: Proficiency and use of non-generic use of English definite article by L1- Persian EFL learners
}

\author{
Masoumeh Ahmadi Shirazi \\ University of Tehran, Faculty of Foreign Languages and Literatures, Iran \\ ${ }^{*}$ Corresponding author ${ }^{1}$
}

\begin{abstract}
.
This study was an attempt to hit upon the performance of the Persian speakers of English on the four non-generic uses of the English definite article. To that end, 80 participants in the study were grouped into three categories of low, intermediate, and advanced learners of English by using a Nelson Quick Test. Following that an 81-item instrument stripped of its definite articles was given to each of the participants. In 40 of the sentences, there were a total of forty deleted obligatory uses of the, i.e., 10 for the Cultural Use group (CU), 10 for Situation Use SU, 10 for Structural Use (STU) and 10 for Textual Use (TU). The remaining 41 sentences were included as distracters. Multiple Analysis of Variance (MANOVA) was run to see if proficiency level has an effect on learners' supplying of the in obligatory contexts for all four uses and the results showed that the variable of proficiency does induce changes in the SU and TU use of definite article. In order to check if four major categories of non-generic use of the pose different levels of difficulty to learner, four one-way between-groups ANOVAs were run: the results were nonsignificant for four non-generic uses of definite article the. The findings, though, indicate the fact that more attention will be allocated to teaching definite article to learners with different language backgrounds and proficiency levels.
\end{abstract}

Keywords: English Article system; discourse; generic use; indefinite articles; grammar

\section{Introduction}

The English article system has long been a subject of interest for linguists, due to its complex usage and the difficulty involved in analyzing it. Master (2002) provides three reasons for this difficulty:

(1) the articles, which include the words $a$, an, and $\varnothing$, the invisible zero/null article, are among the most frequently occurring function words in the language making continuous conscious rule application difficult over an extended stretch of discourse, (2) function words are normally unstressed and consequently very difficult if not impossible for a NNS to discern, thus affecting the availability of input in the spoken mode, and (3) the article system stacks multiple functions onto a single morpheme, a considerable burden for the learner, who generally looks for a one-

\footnotetext{
${ }^{1}$ Masoumeh Ahmadi Shirazi, University of Tehran, Faculty of Foreign Languages and Literatures, Department of English and Literature, email: ahmadim@ut.ac.ir, Tehran, Iran.
} 


\section{Global Conference on Education \& Teaching}

form-one-function correspondence in navigating the labyrinth of any human language until the advanced stages of acquisition. (p. 332)

It was Bickerton (1981) who said that the systematic classification of the semantic function of an NP is determined by two binary discourse features: (a) whether a noun is a specific referent $\left(+/ \_S R\right)$, and (b) whether the hearer knows the referent (+/_HK). Based on such an analysis NPs fall into four major categories:

Type 1 is $[-\mathrm{SR},+\mathrm{HK}]$, also known as "generics," where the indefinite, the definite, or, if the noun is plural, the zero article is used. Take this sentence: a/the dog is a loyal accompany. Type 2 is $[+\mathrm{SR},+\mathrm{HK}]$ where the definite article is required. It includes four subcategories a) unique referent or conventionally assumed unique referent, such as the pope; (b) referent physically present, as assumed unique referent as in the example, Pass me the salt; (c) referent previously mentioned (e.g., a resident in a small village with one church tells another resident, "My wife is at the mosque"). Type 3 is $[+\mathrm{SR},-\mathrm{HK}]$, where the indefinite, or, if the noun if plural, zero article is called for. There are two subcategories in this type: (a) first mention in the discourse of a [+SR] NP assumed to be unknown to the hearer, as in tom bought a car, and (b) first mention of a $[+\mathrm{SR}] \mathrm{NP}$ that follows the existential have and in assumed to be unknown the hearer, as in My computer has a new sound car. Type 4 is [-SR, -HK], where the indefinite article, or, if the noun is plural, zero article if required. Yet this type itself consists of four subcategories: (a) equative NPs, as in she is a single parent; (b) NPs in a negation statement, as in I don't have a pen.; (c) NPs that appear in questions such as: Do you have a light?, and (d) NPs in hypothetical statements, as in If I had had more money, I would have bought a new car. This classification illustrates clearly that the four systematic type of NPs each have different discourse and referential constraints and thus call for choosing between $a$, the, and zero to denote the previously-mentioned constraints. It is this knowledge of the systematic types of NPs and the article(s) used with each type that that enables English speakers and writers to mark the NPs in discourse with the appropriate articles. As was mentioned in the literature, Thomas (1989) and Butler (2002) added a fifth category to this model titled idiomaticity (e.g., all of a sudden, living hand to mouth) which, like generics, can include $a$, the, and zero.

Article use, according to Ionin, Ko, and Wexler (2004), can be divided into two systems: definiteness and specificity. They contend that definiteness happens when "the speaker and the hearer presuppose the existence of a unique individual in the set denoted by the NP" (p. 5); when "the speaker intends to refer to a unique individual in the set denoted by the NP, and considers this individual to possess some noteworthy property" (Ionin, Ko, \& Wexler, 2004).

The use of the is a challenge and has given rise to controversial findings which relate different factors to its complex nature. Some people attempted to classify its use; two major categories are generic and non-generic use (Celce- Murcia \& Larsen Freeman, 1999; Hawkins, 1978; Quirk, Greenbaum, Leech, \& Svartvik, 1985).

Difficulty in learning the definite article stems from different sources. Some people associate it with role first language plays in the acquisition of the. Chrabaszcz and Jiang (2014) assert that L1 poses difficulty learning the definite article in English. Sun (2016) also substantiates the easier and faster acquisition of +Art (with article system) group than - Art (without article system) group suggesting that "+Art” ELL acquired English articles faster than "- Art" ELL and that when two languages were similar, positive transfer would occur" (p. 1). 


\section{Global Conference on Education \& Teaching}

Here it seems necessary to clearly define two categories of the use of the definite article the: generic and non-generic. Generic use, according to Liu and Gleason (2002), refers to:

...cases where it is used to mean either a species, a race, or people of a nation. It is usually used with a singular noun, as in the German is very athletic, although it may also be used as some grammarians (Celce- Murcia \& Larsen Freeman; Christopherson, 1939) suggested, with Plural nouns, as in The Germans are very athletic. (p. 5)

All other cases of the use of definite article the belong to non-generic category which have been defined and classified by scholars among whom we can name Hawkins (1978) with his Location theory categorizing non-generic uses to eight types and then Liu and Gleason suggested four non-generic use of the definite article the namely textual, structural, situation, and cultural use. Their descriptions are as follows: 1. Cultural Use (CU): resorts to information considered unique and shared by all the people who speak the language (e.g., President Bush lives in the White House), 2. Situation Use (SU): the listener relies on information readily available within their sensory reach or information locally available (e.g., My father is at the mosque (With a first mention noun), 3. Structural Use (SU): the listener or reader uses structural information that lies on a modifier such as a prepositional phrase, a relative clause, or certain adjectives (e.g., The Movies that are shown here are all R- rated), and 4. Textual Use (TU): the listener or reader relies on textual information, i.e., a noun that has been previously referred to or is related to a previously mentioned noun (e.g., We went to a wedding yesterday. The bride was really pretty.). Several studies show contradictory result in the use of nongeneric use of the stating that for different first language learners of English as a Foreign language, four categories pose different difficulty. Some believe that for Egyptian EFL learners, structural and textual are the most difficult following by situation and cultural (Abdel Kader, 2017). In a recent study by Giles (2019), L1-Azerbaijani EFL learners, in missed obligatory uses of non-generic definite article, cultural and structural uses equally presented difficulty while the situation use posed the least difficulty. The study did not take into consideration the effect that may induce differences in the use of non-generic definite article by learners with different proficiency levels.

Another issue that relatively pertains to the acquisition of non-generic and/or generic use of definite article in English is the level of proficiency. Some people believe that the more command of language, the sooner and better you will learn how to use articles. For example, KoÇ (2015) did a study on Turkish learners of English as a Foreign Language the result of which corroborated the importance of proficiency. The performance of learners of this study showed the omission of articles by the intermediate level but that was not the case with lowadvanced learners of English as a Foreign Language. Shirazi and Shabanluie (2014) also found a positive effect of proficiency in the performance of L1-Persian EFL learners. Taking all the above-mentioned issues into account, the study makes an attempt to answer two questions: 1 . Does proficiency have any effect on the Iranian EFL learners' supplying of English article the in obligatory contexts for all four uses?, and 2. Does each of the four major categories of the non- generic uses of English article the- namely the cultural use, situation use, structural use, and textual use pose different levels of difficulty to Iranian EFL learners? To further investigate these assumptions, we switch to explain how we proceeded to find answers to these questions. 


\section{Methods}

This section portrays the selection of subjects of the study, the instruments used in the study, how data were gathered and analyzed and finally the findings will be scrutinized and discussed.

\subsection{Participants}

A total of 80 English students at the University of Tehran's Faculty of Foreign Languages contributed to the study. They were majoring in English literature, translation, and TEFL (Teaching English as a Foreign Language). The participants included both male and female students with their age as varied as 19 and 26. Majority of the participants were doing their BA in any of the majors in English and the rest were MA students in TEFL or English literature.

\subsection{Instruments}

Results of a Nelson Quick Test (NQT) administered to all the participants were utilized as a criterion to categorize them into three proficiency groups with 32 in the advanced category, 31 in the intermediate group, and 17 in the basic category. The participants were each handed a five-page copy of the Nelson Quick Test to answer in a designated answer sheet. The test contained 100 multiple- choice items covering the participants' knowledge of grammar and vocabulary. Mean score differences were significant by running one-way ANOVA to compare the three groups. The scores were between 98 as the maximum and 70 as the minimum. Tab. 1 and Tab. 2 show these pieces of information.

Table 1. Descriptive statistics for the participants of the study

\begin{tabular}{|l|l|l|l|l|l|}
\hline Group & $\mathrm{N}$ & Mean & Std. deviation & Minimum & Maximum \\
\hline Advanced & 32 & 91.97 & 3.267 & 88 & 98 \\
\hline Intermediate & 31 & 84.68 & 1.620 & 82 & 87 \\
\hline Basic & 17 & 75.53 & 3.430 & 70 & 81 \\
\hline Total & 80 & 85.65 & 6.794 & 70 & 98 \\
\hline
\end{tabular}

Table 2. Comparing mean differences between groups by ANOVA

\begin{tabular}{|l|l|l|l|l|l|}
\hline NQT & $\begin{array}{l}\text { Sum of } \\
\text { squares }\end{array}$ & df & Mean square & F & Sig. \\
\hline Between groups & 3048.222 & 2 & 1524.111 & 196.256 & .000 \\
\hline Within groups & 597.978 & 77 & 7.766 & & \\
\hline Total & 3646.200 & 79 & & & \\
\hline
\end{tabular}

Furthermore, an instrument containing 81 sentences was used in the study. In 40 of the sentences, there were a total of forty deleted obligatory uses of the, i.e., 10 for the cultural use group (CU), 10 for situation use SU, 10 for structural use (SU) and 10 for textual use (TU). The remaining 41 sentences were included as distracters. It is worth mentioning that none of the distracters required the to be added to them. In other words, they all required the zero article. To ensure that the answer key contained all the correct answers, the instrument was email to the United States of America via email. Twenty American native speakers of English took the instrument confirming the answer key provided for the instrument.

Efforts were made for the items used in the instrument to unambiguous and appropriate. The sentences used in the instrument were prepared after consulting with grammar books like the 


\section{Global Conference on Education \& Teaching}

example sentences in Celce Murcia and Larsen Freeman (1999) and Hawkins (1978). The next step was to simply delete the obligatory uses of the that were going to be tested from the sentences. It was a difficult task, however no as demanding as preparing the distracter items particularly for the situation and textual use. That was because the cultural and structural uses were, by definition, quite straightforward, but finding distracters the other two uses, namely situation and textual, was a monumental task. The cultural use, for instance, is often conventional. Not all names of places and diseases require the definite article. Therefore, for cultural distracters, the names of diseases or places that do not take the, such as polio and Yellow Stone Park were simple included in the instrument. Similarly, not all the NPs that have an explanatory modifier call for the, so for structural use distracters, NPs that contained a modifier but sis not require the use of the definite article (e.g., Children growing up with both parents are healthier than children growing up with only one parent).

Unlike in cultural and structural uses, the definite article is always used in textual and situation uses- that is, it is always required with specific referent in known situation or with a referent mentioned again. For develop distracters for situation use the sentences used had a scenario whereby something was referred to in an immediate situation but cultural practice makes the unacceptable. For example, in sentence 79, the game host says to the contestant, "What's behind door number one? the is not allowed before door number one because such NPs take the null article, whereas phrases like the first door take the. The definite article therefore becomes unacceptable here not because the referent is not known in an immediate situation but because of cultural practice. For textual- use distracters, sentences in which a noun appears twice but, in its second appearance, is used as a general reference specifically to what has been mentioned earlier (e.g., At the zoo I saw several tigers. I think tigers are beautiful animals).

As for the test format no blanks were left for the obligatory uses of the nor for the unnecessary the distracters. The subjects were simply asked to read the sentences and insert the wherever they deemed it necessary. The rationale for not including blanks was that if we did, some of the students, especially the so-called low-level students, might fill every single blank with the, making the resultant data very unreliable. This later happened to be a good decision as it yielded some additional data covering the territory of ungrammatical or general overuse of the.

\subsection{Data collection procedure}

At first, the participants sat for Nelson Quick Test (NQT) which consisted of two parts: grammar and vocabulary. Two raters were involved in scoring the papers including the researcher. Following that each participant got a typed copy of the instrument to fill out in concordance with the superscripted directions presented. Moreover, the participants were disallowed to use their dictionaries in the process. To ensure the participants do no crib from their neighboring friends, the researcher invigilated the whole exam session. It is worth mentioning that the participants were not informed about the distracters- a decision that gained the study some valuable data.

\subsection{Results and discussion}

To answer if proficiency have any effect on the Iranian EFL learners' supplying of English article the in obligatory contexts for all four uses, MANOVA was run. Since we have a 


\begin{tabular}{|c|l|l|l|l|l|l|l|}
\hline Source & $\begin{array}{l}\text { Dependent } \\
\text { variable }\end{array}$ & $\begin{array}{l}\text { Type III } \\
\text { Sum of } \\
\text { Squares }\end{array}$ & df & $\begin{array}{l}\text { Mean } \\
\text { square }\end{array}$ & F & Sig. & $\begin{array}{l}\text { Partial Eta } \\
\text { Squared }\end{array}$ \\
\hline \multirow{3}{*}{ NQT } & $\mathrm{Cu}$ & 94.163 & 26 & 3.622 & 1.324 & .191 & .394 \\
\cline { 2 - 8 } & $\mathrm{Su}$ & 81.538 & 26 & 3.136 & 2.212 & .007 & .520 \\
\cline { 2 - 8 } & $\mathrm{Stu}$ & 50.792 & 26 & 1.954 & 0.591 & .927 & .225 \\
\cline { 2 - 8 } & $\mathrm{Tu}$ & 60.079 & 26 & 2.311 & 1.519 & .098 & .427 \\
\hline
\end{tabular}

dependent variable with four types, multiple analysis of variance was chosen to analyze the data; moreover, MANOVA lessens the risk of inflated Type I error meaning that if we run a number of ANOVAs instead, there is a risk to find a statistically significant result while this is not true, in fact. According to Pallant (2005):

Because you are looking at a number of separate analyses here, it is suggested that you set a higher alpha level to reduce the chance of a Type 1 error (i.e., finding a significant result when there isn't really one). The most common way of doing this is to apply what is known as a Bonferroni adjustment. In its simplest form this involves dividing your original alpha level of .05 by the number of analyses that you intend. (p. 259)

Now that we have four types of non-generic use of definite article the, we divide 0.05 into four: the new alpha level would be 0.0125 . If the probability value is less than 0.0125 , the result is significant.

Table 3. MANOVA to compare four non-generic use of the by three different proficiency groups

As can be seen in Tab. 3, just in cases of situation use and textual use, proficiency level has a role to play while the results for the other two, that is cultural and structural uses, are nonsignificant for L1-Persian learners of English as a Foreign Language. Still, there are some reservations regarding the use of non-generic definite article for learners with different proficiency level and language background. Even there is not a robust evidence for the accuracy of the use of generic/non-generic articles by English native speakers. To answer whether each of the four major categories of the non- generic uses of English article the-namely the cultural use, situation use, structural use, and textual use pose different levels of difficulty to Iranian EFL learners, for each type of non-generic use of the definite article the, a one-way ANOVA was run to examine level of difficulty that four different types of non-generic use of the may impose on Iranian learners of English as a Foreign Language. The result of analyses showed no significant difference in the difficulty that the four categories pose. It is noteworthy to mention that the results suffer different sample sizes, therefore the issue of Type I error, unfortunately, may modify the result of the study, thus there is a need felt to try other studies with harmonic sample sizes to obtain more reliable results.

\section{Conclusion}

The first research question depicted a picture that is illuminating to some extent. Proficiency levels of learners can contribute to the acquisition of non-generic use of English definite article although some categories are affected by proficiency level and some are not. This is the place of contradiction among scholars. Although in the past scholars have pointed to the importance of proficiency level in learning article system in English in general (Butler, 2002; KoÇ, 2015; Lesniewska, 2016; Liu \& Gleason, 2002; Pica, 1983; Shirazi \& Shabanluie, 2014 amongst 
others), still there are other factors that need to be factored in second language studies as such the most important of which is first language of EFL learners.

The article system of English language is hard to learn for non-native and English native alike. While less challenging structures can be acquired relatively rapidly, it may take an ESL learner a long time to develop a proficiency in a complex language aspect such as the proper use of articles. These structures are difficult to teach, and still more difficult to learn. Late acquisition of articles accords with a number of factors. Most of the world's languages (Russian, African, and Asian languages) do not have equivalents for "the", "a" and "an". Moreover, in the languages that do have these structures, the rules for using them differ from the rules for using them in English. Broadly, by English rules, the definite article "the" signals given--shared-information, while the indefinite "a" or "an" marks new--unknown--information. Regarding the acquisition of articles, learners need to be informed of patterns, and then directed to read and look for these patterns in their reading. With careful instruction in patterns of article usage, in combination with a learner's extensive reading and noticing, these patterns of formal article usage can be acquired in due time. Still, producing articles with some accuracy generally coincides with an advanced proficiency in English. The difficulty of acquisition of articles will be exacerbated for speakers whose native languages lack them.

L1-Persian studies concerning the acquisition and use of English article system are meager in number (Ansarin, 2004; Chabok \& Khodareza, 2017; Faghih, 1997; Joolaee \& Ghonsooly, 2015; Momenzade, Youhanaee, Kassaian, 2014; Shirazi \& Shabanluie, 2014), hence any sort of conclusive claim should be made with reservations in mind. The research on English article system, especially non-generic use of definite article the is in its infancy because many a variable have not incorporated in the study that would otherwise modify the results of studies. This study was also limited since the path learners go through to learn the use of the that is the acquisition process, the method they are taught to use to learn, their mother tongue, years of exposure to English language, age of first exposure, different age groups, K-12 students as participants and so many other variables have not been considered and may need to be closely investigated. Future studies demand more attention to those variables that have pictured controversy in previous studies.

\section{References}

Abdel Kader, A. S. A. (2017). Acquisition of the non-generic use of the definite article "the" by Egyptian EFL learners, Journal of Faculty of Education for Educational Sciences, vol 41, pp. 15-54.

Ansarin, A. A. (2003). Non-generic use of the definite article the by Persian learners, Journal of Faculty of Letters and Humanities, vol 47, pp. 1-11.

Bickerton, D. (1981). Roots of language. Ann Arbor, MI: Karoma

Butler, Y. G. (2002). Second language learners' theories on the use of English articles: An analysis of the metalinguistic knowledge used by Japanese students in acquiring the English article system, Studies in Second Language Acquisition, vol 24, pp. 451-480. 
Celce-Murcia, M, and Larsen-Freeman, D. (1999). The Grammar Book. Boston, Mass: Heinle

\& Heinle Publishers.

Chabok, M. R. and Khodareza, M. (2017). The effects of teaching articles based on Huebner's

model on Iranian intermediate EFL learners' use of articles, Journal of Second and Multiple Language Acquisition, vol 5, pp. 73-83.

Chrabaszcz, A. and Jiang, N. (2014). The role of the native language in the use of the English non-generic definite article by L2 learners: A cross-linguistic comparison, Second Language Research, vol 30, pp. 351-379.

Faghih, E, (1997). A contrastive analysis of the Persian and English definite article, International Review of Applied Linguistics, vol 35, pp. 127-138.

Giles, J. D. (2019). The L2 English non-generic definite article use of L1 Azerbaijani speakers [Master's thesis, St. Cloud State University.

https://repository.stcloudstate.edu/cgi/viewcontent.cgi?article=1010\&context=tesl etds

Hawkins, J. (1978). Definiteness and indefiniteness. San Diego, CA: Academic Press.

Ionin, T., Ko, H., and Wexler, K. (2004). Article semantics in L2 acquisition: The role of specificity, Language Acquisition, vol 12, pp. 3-69.

Joolaee, G. M. and Ghonsooly, B. (2015). Acquisition of the article "The" by Persian speakers, Procedia - Social and Behavioral Sciences, vol 192, pp. 438-446.

KoÇ, K. D. (2015). The non-generic use of the definite article the in writing by Turkish learners of English, Hacettepe University Journal of Education, vol 30, pp. 56-68.

Lesniewska, J. (2016). The use of articles in L2 English: A phraseological perspective, Studies in Second Language Learning and Teaching, vol 6, pp. 203-224.

Liu, D. and Gleason, L. G. (2002). Acquisition of the article the by nonnative speakers of English: An analysis of four non-generic uses, Studies in Second Language Acquisition, vol 24, pp. 1-26.

Master, P. (2002). Information structure and English article pedagogy, System, vol 30, pp. 331-348. 


\section{Global Conference on Education \& Teaching}

Momenzade, M., Youhanaee, M. and Kassaian, Z. (2014). Article choice by Persian EFL learners: Evidence against the Fluctuation Hypothesis?, International Journal of Research Studies in Language Learning, vol 3, pp. 29-42.

Pallant, J. (2005). SPSS survival manual: A step by step guide to data analysis using SPSS for Windows (Version 12). Australia: Allen and Unwin.

Pica, T. (1983). Adult acquisition of English as a second language under different conditions of exposure, Language Learning, vol 33, pp. 465-497.

Quirk, R., Greenbaum, S., Leech, G. and Svartvik, J. (1985). A comprehensive grammar of the English language. London: Longman.

Shirazi, A. M. and Shabanluie, S. (2014). The suppliance of definite and indefinite articles: The role of test method and proficiency, Iranian EFL Journal, vol 10, pp. 129-144.

Sun, G. (2016). The acquisition of English articles by second language learners: The sequence, differences, and difficulties, Sage Open, pp. 1-8.

Thomas, M. (1989). The acquisition of English articles by first- and second-language learners,

Applied Psycholinguistics, vol 10, pp. 335-355. 